\title{
Effect of adrenocorticotrophic hormone on the development of oestrogen-induced changes and hyperplasia formation in the mouse uterus
}

\author{
A. G. Gunin, V. Emelianov and A. S. Tolmachev \\ Department of Histology Medical School Chuvash State University, \\ PO Box 86, 428034, Cheboksary, Russia
}

The aim of this study was to examine the role of adrenocorticotrophic hormone (ACTH) in proliferative and morphogenetic reactions in the uterus under continuous oestrogen treatment. Ovariectomized mice received injections of oestradiol dipropionate or vehicle once a week $(2 \mu \mathrm{g}$ per $100 \mathrm{~g})$, and injections of ACTH $(10 \mu \mathrm{g}$ per $100 \mathrm{~g})$ once a day or once a week for 30 days. Additional control mice received oestradiol and saline, vehicle of oestradiol, and ACTH once a day or once a week, or vehicle of ACTH, for 30 days. This study shows for the first time that ACTH affects oestrogen-dependent reactions in the uterus. Treatment with ACTH once a day resulted in a decrease in uterine mass, in cell proliferation (assessed by the number of mitotic and bromodeoxyuridine (BrdU)-labelled cells) and in the incidence of endometrial hyperplasia, in particular complex and atypical hyperplasia. Treatment with
ACTH once a week led to a marked reduction in the incidence of endometrial hyperplasia, a slight increase in uterine mass and had almost no effect on cell proliferation. Daily treatment with ACTH reduced the concentration of oestrogen receptor $\alpha$ in all uterine compartments, but weekly ACTH administration had the opposite effect. Expression of glucocorticoid receptors, $\beta$-catenin and glycogen synthase kinase- $3 \beta$ in uterine tissues was lower in animals treated with oestradiol and ACTH once a day or once a week. When olive oil was used instead of oestradiol, treatments with ACTH did not produce detectable changes in all parameters examined. Thus, glucocorticoid receptor, oestrogen receptor $\alpha, \beta$-catenin and glycogen synthase kinase- $3 \beta$ are involved in the effects of ACTH on oestrogeninduced changes in uterine mass, cell proliferation and the incidence of hyperplasia.

\section{Introduction}

Oestrogenic hormones produce marked changes in the uterus and can lead to the formation of endometrial hyperplasia and cancer (Martin et al., 1973a; Niwa et al., 1998; Liehr, 2000). Therefore, oestrogen action in the uterus must be strictly regulated as a protective mechanism against cancer. A variety of factors modify uterine sensitivity to oestrogens (Couse and Korach, 1999; Emons et al., 2000). Among these factors are glucocorticoid hormones, which exert a strong influence on the action of oestrogen in the uterus. Many studies have shown that glucocorticoids have an inhibitory effect on proliferation induced by short-term oestrogen treatments (Tchernitchin et al., 1975; Campbell, 1978; Markaverich et al., 1981; Monheit and Resnik, 1981; Stewart et al., 1983; Rabin et al., 1990; Bigsby, 1993; Sahlin, 1995). A single injection of oestrogen given after long-term treatment with the synthetic glucocorticoid triamcinolone produced a progesterone-like enhancement of proliferation in stromal and myometrial cells (Gunin, 1998; Gunin et al., 2000). Combined long-term treatment with both oestradiol and the synthetic glucocorticoid dexamethasone did not induce an increase in uterine mass

Email:drgunin@yahoo.com or cell proliferation, prevented changes in mitosis orientation and in morphogenetic parameters, and inhibited endometrial hyperplasia formation (Gunin et al., 2001). Thus, the effect of glucocorticoids on oestrogen-induced processes in the uterus depends on prolongation of their action, on the duration of oestrogen treatment, on the doses of both hormones and on the type of glucocorticoid used. Moreover, treatment with exogenous glucocorticoids has been used in all studies in this area of research. However, neuroendocrine consequences of treatment with exogenous glucocorticoids differ from those produced by increases in endogenous concentrations of these hormones. There is a decrease in the activity of the pituitary-adrenal system when exogenous glucocorticoids are used (Zennaro, 1998). In contrast, an increase in the concentration of endogenous glucocorticoids is always accompanied by enhanced activity of the pituitary-adrenal system, a key component of which is adrenocorticotrophic hormone (ACTH) (Zennaro, 1998). Consequently, the effect of treatment with exogenous glucocorticoids on oestrogen-dependent processes in the uterus may be dissimilar to that induced by increased activity of the pituitary-adrenal system. It would be useful to know how enhanced activity of the pituitary-adrenal system affects the action of oestrogens in the uterus, especially their chronic action, which produces shifts in uterine 
morphogenesis and can lead to hyperplasia and cancer formation (Niwa et al., 1998; Gunin et al., 2001, 2002). However, at present, there are no data on this problem. Therefore, the aim of this work was to examine oestrogendependent processes in the uterus under chronic treatment with ACTH.

\section{Materials and Methods}

\section{Animals}

All procedures were performed in accordance with the Guidelines on the Handling and Training of Laboratory Animals published by the Universities Federation for Animal Welfare and with the Chuvash State University rules for work with laboratory animals. White non-linear female mice (20-21 g) were used. Animals were obtained from the Animal Department of Chuvash State University (Cheboksary) and were housed under the standard conditions of the vivarium with free access to water and food (mouse chow). Mice were ovariectomized 1 week before the experiments were started. All surgical procedures were performed under anaesthesia with ketamine and droperidol (70 and $0.1 \mathrm{mg} \mathrm{kg}^{-1}$, respectively, i.p.; Gedeon-Richter, Budapest).

\section{Treatments}

Experimental animals were subdivided into several groups according to treatment protocols. The first group of mice received s.c. injections of oestradiol dipropionate in olive oil (Minmedprom, Rostov-Don) once a week at a dose of $2 \mu \mathrm{g}$ per $100 \mathrm{~g}$ of body weight and s.c. injections of synthetic ACTH in long-acting form once a day at a dose of $10 \mu \mathrm{g}$ per $100 \mathrm{~g}$ of body weight $\left(\mathrm{ACTH}^{1-24}\right.$, Synacthen depot; Novartis Pharma AG, Basel), for 30 days. The second group received injections of oestradiol at the same dose once a week, injections of ACTH (10 $\mu$ g per $100 \mathrm{~g})$ once a week and injections of saline $(0.05 \mathrm{ml}$ per mouse, $0.9 \%$ $(\mathrm{w} / \mathrm{v})$ sodium chloride) on the days when ACTH was not administered, for 30 days. The third group of animals received injections of oestradiol once a week and injections with saline once a day, for 30 days. Additional groups received vehicle (olive oil) instead of oestradiol and the same treatments with ACTH and saline. There were 11 mice in each oestradiol-treated group and 5 mice in each vehicle (olive oil)-treated group. All animals were injected i.p. with bromodeoxyuridine (BrdU; Sigma Chemical Co., St Louis, $\mathrm{MO}$ ) dissolved in saline at $2 \mathrm{~h}$ before the tissues were removed. The dose of BrdU was $5 \mathrm{mg}$ per $100 \mathrm{~g}$ of body weight. Uteri, thymi and adrenal glands were removed under deep ether anaesthesia on day 3 after the last oestradiol or vehicle injection. Uteri were weighed and the middle segments of the uterine horns were placed in modified Bouin's fixative (Gunin et al., 2000) for $6 \mathrm{~h}$ at room temperature, and were dehydrated and embedded in paraffin wax. Uteri were oriented transversely and cut into sections of 5-7 $\mu \mathrm{m}$. Adrenal glands and thymi were weighed immediately after removal to monitor the effectiveness of the ACTH treatments.

\section{Uterine histology}

Histological changes in the uterus were analysed and classified according to Scully et al. (1994). The extent of hyperplastic or neoplastic changes in the endometrium was determined by subdividing the uterine glands into four morphological types, as described by Gunin et al. (2001): (i) normal glands; (ii) cystic glands; (iii) glands with daughter glands; and (iv) conglomerate of glands. The number of each type of gland was calculated in randomly selected sections. At least three sections from each animal were examined. Results are expressed as the percentage of each type of gland. The epithelium of all glands in randomly selected sections was examined and classified as simple, pseudostratified or stratified (multilayered). The percentage of glands with each type of epithelium was calculated.

\section{Determination of the incidence of mitotic and BrdU- labelled cells}

Proliferative processes were assessed by the number of mitotic and BrdU-labelled cells. Mitoses were counted in sections stained with iron haematoxylin. BrdU was detected immunohistochemically using anti-BrdU mouse monoclonal antibody conjugated with alkaline phosphatase (Boehringer Mannheim GmbH, Mannheim) diluted 1:20, as described by Gunin et al. (2000). Alkaline phosphatase activity was determined by the use of naphtol AS-BIphosphate and new fuchsin as chromogens. All results are expressed as the percentage of mitotic or labelled cells. The numbers of mitotic and BrdU-labelled cells in luminal epithelium, glandular epithelium, stromal cells and myometrial cells were determined as described by Gunin et al. (2001). At least 3000 epithelial and 10000 stromal or myometrial cells were assessed per mouse.

\section{Detection of oestrogen receptor $\alpha$, glucocorticoid receptor, $\beta$-catenin and glycogen synthase kinase- $3 \beta$}

Oestrogen receptor $\alpha$, glucocorticoid receptor, $\beta$-catenin and glycogen synthase kinase-3 $\beta$ were detected using routine indirect immunohistochemical staining. Rabbit antioestrogen receptor $\alpha$ polyclonal antibody (Santa Cruz Biotechnology Inc., Santa Cruz, CA) diluted 1:50, rabbit anti-glucocorticoid receptor polyclonal antibody (Santa Cruz Biotechnology Inc.) diluted 1:50, rabbit anti- $\beta$-catenin antiserum (Sigma Chemical Co.) diluted 1:50, and rabbit anti-glycogen synthase kinase-3 $\beta$ polyclonal antibody (gift from Dr Miho Takahashi, Mitsubisi Kasei Institute of Life Science, Tokyo) diluted 1:25 (Takahashi et al., 2000) were used as primary antibodies. For the detection of oestrogen 
receptor $\alpha$, glucocorticoid receptor and glycogen synthase kinase- $3 \beta$, goat anti-rabbit immunoglobulin $G$ antibody conjugated to alkaline phosphatase (Jackson ImmunoResearch Laboratories Inc., West Grove, PA) was used as secondary antibody, and alkaline phosphatase activity was revealed using naphtol AS-BI-phosphate and new fuchsin as chromogens. For $\beta$-catenin, goat anti-rabbit immunoglobulin G antibody conjugated to peroxidase (DAKO, Glostrup) was used as secondary antibody, and peroxidase activity was determined by use of the hydrogen peroxide and diaminobenzidine technique; slides were also preincubated in $0.1 \%(\mathrm{v} / \mathrm{v})$ hydrogen peroxide in distilled water for $10 \mathrm{~min}$ to block endogenous peroxidase activity. For glycogen synthase kinase-3 $\beta$ detection, sections were preincubated in $20 \mathrm{mmol}$ citrate buffer $\mathrm{I}^{-1}(\mathrm{pH} 5.5)$ in a microwave oven (Samsung, G643S, $800 \mathrm{~W}$ ) for $10 \mathrm{~min}$ at full power (Takahashi et al., 2000). Control sections were stained in a similar manner, except that the primary antibody was replaced with normal rabbit serum. Sections from all mice were processed simultaneously for each antigen to avoid possible differences in the intensity of staining, so that all sections were incubated in exactly the same Tris-buffered saline, the same mixtures of primary and secondary antibodies, the same mixture for development of enzyme activity, for the same duration and at the same temperature. The intensity of immunostaining was quantified by photometric measurement of absorbance for positively stained components of a tissue (Gunin et al., 2002). Photometry was performed using a light microscope and FMEL-1A microspectrophotometer (LOMO, St Petersburg) by measuring the intensity of light passing through equivalent areas occupied by positively stained structures $(F)$ and by structures with no staining $\left(F_{0}\right)$. Absorbance (light absorption) was calculated from the formula: absorbance $=\lg \left(F_{0} / F\right)$. For oestrogen and glucocorticoid receptors, positive staining was detected in the nuclei of all uterine tissues (luminal epithelium, glandular epithelium, stromal cells, myometrial cells). Therefore, the intensity of light passing through the nuclei $(F$; positive staining) and through the cytoplasm $\left(F_{0}\right.$; negative staining) was measured. For $\beta$-catenin and glycogen synthase kinase- $3 \beta$, positive immunostaining was detected in the cytoplasm of luminal and glandular epithelia, but not in endometrial stromal cells. Consequently, the intensity of light passing through the cytoplasm of uterine epithelial cells ( $F$; positive staining) and through the endometrial stromal cells ( $F_{0}$; negative staining) was used. The degree of expression was considered as the optical density value (Gunin et al., 2002). At least 100 nuclei were analysed for each structure in each mouse.

\section{Statistical analysis}

Arithmetic means and standards errors were calculated for each data group. The significance of differences was determined by the non-parametric Mann-Whitney $U$ test (uterine mass, cell proliferation, oestrogen receptor, glucocorticoid receptors, $\beta$-catenin, glycogen synthase kinase- $3 \beta$ ) and by the chi-squared test (types of gland, types of epithelium, pathology).

\section{Results}

\section{Mass of thymus and adrenal gland}

The effectiveness of the treatments with ACTH was controlled by weighing the thymus and adrenal gland. Thymus mass was $164.2 \pm 9.4 \mathrm{mg}$ per $100 \mathrm{~g}$ body weight (mean \pm SEM; $n=11$ for each group) in control mice that received oestradiol and saline, $69.8 \pm 12.2 \mathrm{mg}$ per $100 \mathrm{~g}$ body weight in mice treated with oestradiol and ACTH once a day $(P<0.001$ compared with control; Mann-Whitney $U$ test), and $111.9 \pm 9.1 \mathrm{mg}$ per $100 \mathrm{~g}$ body weight for mice treated with oestradiol and ACTH once a week. Adrenal gland mass was $7.3 \pm 0.8 \mathrm{mg}$ per $100 \mathrm{~g}$ body weight in mice treated with oestradiol and saline, $23.1 \pm 1.8 \mathrm{mg}$ per $100 \mathrm{~g}$ body weight in mice treated with oestradiol and ACTH once a day $(P<0.001$ compared with control; MannWhitney $U$ test), and $9.1 \pm 0.7 \mathrm{mg}$ per $100 \mathrm{~g}$ body weight in mice treated with oestradiol and ACTH once a week.

\section{Uterine mass}

Treatment with oestradiol and ACTH once a day resulted in a decrease in uterine mass compared with that in mice treated with oestradiol and saline $(562.4 \pm 39.1$ versus $776.5 \pm 45.6$ in controls; mg per $100 \mathrm{~g}$ body weight, mean \pm SEM; $n=11$ for each group; $P<0.02$ by MannWhitney $U$ test). Treatment with oestradiol and ACTH once a week led to slight increase in uterine mass, but this result was not significant $(874.4 \pm 60.3$ versus $776.5 \pm 45.6 \mathrm{mg}$ per $100 \mathrm{~g}$ body weight in controls).

\section{Uterine histology}

Microscopic examination of uteri of ovariectomized mice that were not treated with oestrogens revealed atrophic endometrium in all cases, independent of additional treatments with ACTH. All endometrial glands in these uteri had a narrow lumen and were round, oval or elongated in shape (a microscopic reflection of simple tubular glands), which was regarded as normal. All glands were lined with simple cuboidal epithelium. In mice injected with oestradiol and saline, abnormal glands, in particular glands with daughter glands and glands forming conglomerates, were often observed (Figs 1 and 2). Glands lined with pseudostratified or stratified epithelium were also found in these uteri (Figs 1 and 2). The histological analysis of the uteri is shown (Fig. 2). Atypical endometrial hyperplasia was diagnosed in $27 \%$ of mice treated with oestradiol.

In uteri of mice treated with oestradiol and ACTH once a day, most of the glands had normal morphology and there were no glands with daughter glands or glands forming conglomerates. In addition, most of the glands were lined with simple cuboidal epithelium, and no glands with 

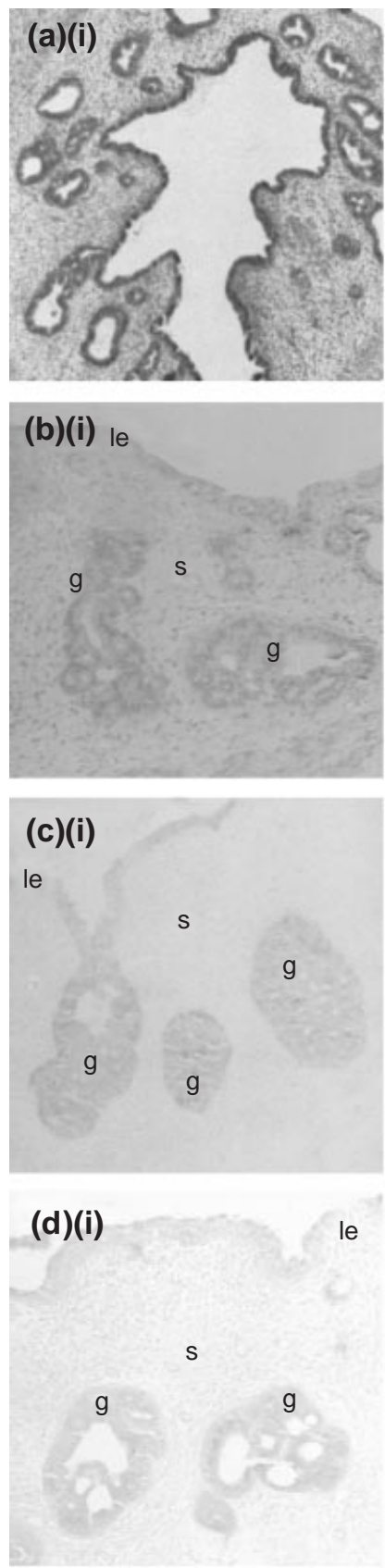
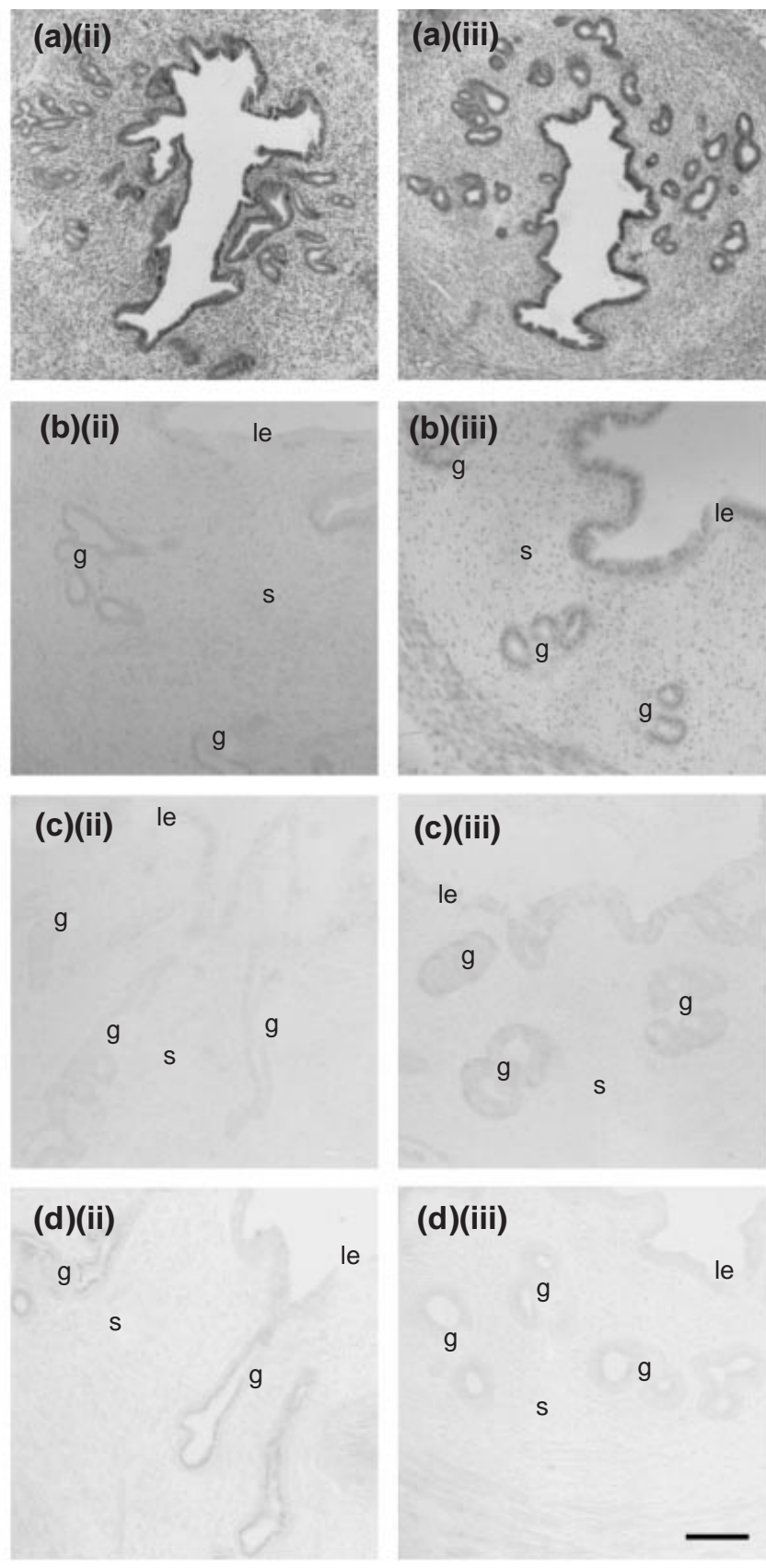

Fig. 1. Photomicrographs demonstrating histological findings (a-i-iii) and immunohistochemical staining for oestrogen receptor $\alpha$ (b-i-iii), $\beta$-catenin (c-i-iii) and glycogen synthase kinase-3 $\beta$ $(d-i-i i i)$ in the uteri of mice treated with oestradiol and saline $(a-i, b-i, c-i, d-i)$, oestradiol and adrenocorticotrophic hormone (ACTH) once a day (a-ii, b-ii, c-ii, d-ii) or oestradiol and ACTH once a week (a-iii, b-iii, c-iii, d-iii), for 30 days. Multiple enlarged glands with small daughter glands inside the walls are observed in (a-i), which shows the uterus of a control mouse treated with oestradiol and saline. Only normal glands of small dimensions and lined with simple cuboidal epithelium are seen in the uteri of mice treated with oestradiol and ACTH once a day (a-ii). There are also only normal glands of round or oval shapes and with simple cuboidal epithelium in the uteri of mice treated with oestradiol and ACTH once a week (a-iii). The immunohistochemical photographs (rows b, c, d) show the presence of abnormal glands with daughter glands and glandular conglomerates in control mice (a-i-d-i), and the presence of normal glands in the uteri of mice treated with oestradiol and ACTH once a day (a-ii-d-ii) or once a week (a-iii-d-iii). There was a marked decrease in the expression of oestrogen receptor $\alpha$ in luminal epithelium (le), glandular epithelium (g) and endometrial stromal cells (s) in the uteri of mice treated with 

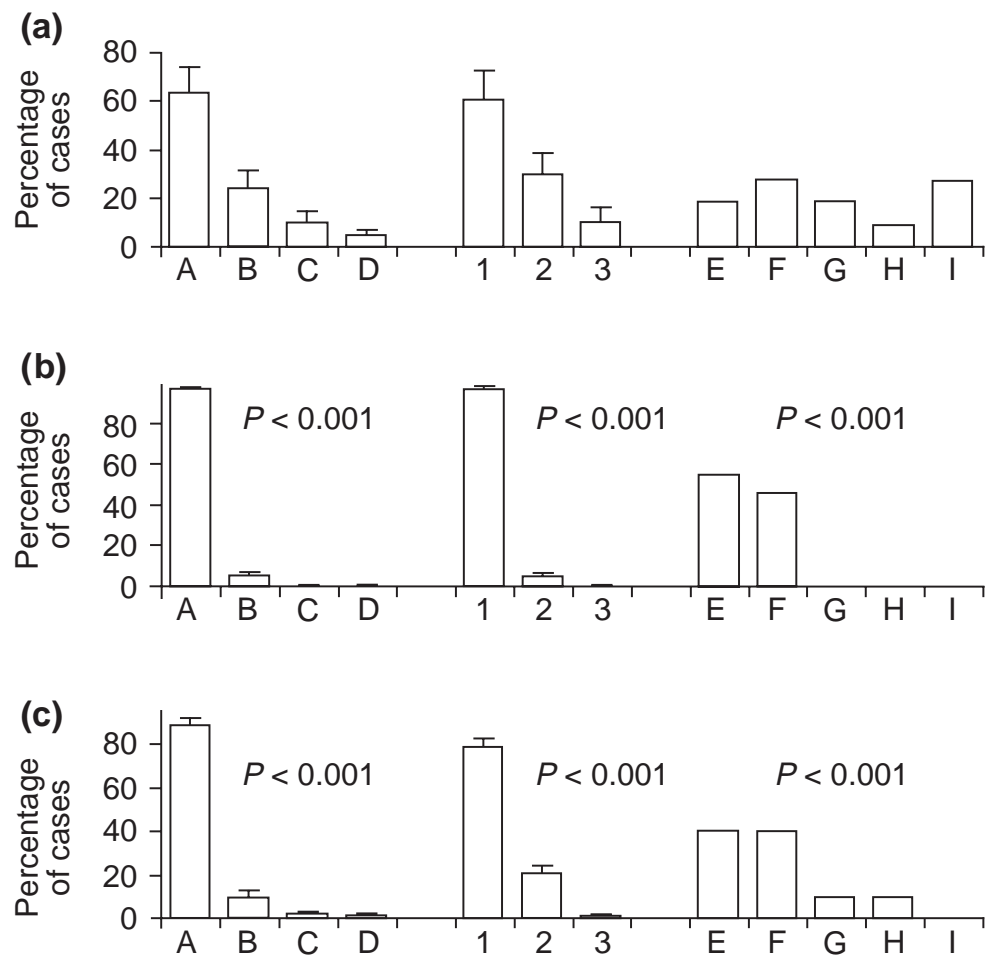

Fig. 2. Types of endometrial gland, types of glandular epithelium, and pathology diagnosis in uteri of ovariectomized mice treated with (a) oestradiol plus saline (control), (b) oestradiol and adrenocorticotrophic hormone (ACTH) once a day, and (c) oestradiol and ACTH once a week, for 30 days $(n=11$ per group). A: normal glands; B: cystic glands; C: glands with daughter glands; D: glands forming conglomerates; 1 : simple columnar epithelium; 2: pseudostratified columnar epithelium; 3: stratified columnar epithelium; E: proliferative endometrium; F: simple hyperplasia; G: cystic hyperplasia; $\mathrm{H}$ : complex hyperplasia; I: atypical hyperplasia. Values are means \pm SEM. $P<0.001 \mathrm{com}-$ pared with controls (significance of differences; chi-squared test).

stratified epithelium were found. In these mice, no cases of complex or atypical endometrial hyperplasia were diagnosed; only uteri with proliferative endometrium or with simple hyperplasia were observed (Figs 1 and 2).

In mice treated with oestradiol and ACTH once a week, the number of abnormal glands was markedly decreased compared with that in control mice treated with oestradiol and saline, and most of the glands were normal (Figs 1 and 2). However, glands with daughter glands and glands forming conglomerates were found in a small number of cases. The incidence of glands with simple epithelium was higher in mice treated with oestradiol and ACTH once a week. In this experimental group, no cases of atypical endometrial hyperplasia were diagnosed. However, a small percentage of uteri with complex or cystic hyperplasia were found. Nevertheless, in the group treated with oestradiol and ACTH once a week there was a large percentage of mice with normal uterine histology (Fig. 2).

\section{Proliferation}

The effect of the treatments on cell proliferation in the uterus was assessed by determining the number of mitotic and BrdU-labelled cells. Treatment with oestradiol and ACTH once a day resulted in a marked decrease in the number of mitotic and BrdU-labelled cells in the luminal

oestradiol and ACTH once a day (b-ii) compared with that in controls (b-i). A small increase in the expression of oestrogen receptor $\alpha$ in glands and luminal epithelium is visible in the uteri of mice treated with oestradiol and ACTH once a week (b-iii) compared with that in controls $(b-i)$. A reduction in the expression of $\beta$-catenin is visible in luminal and glandular epithelium of mice treated with oestradiol and ACTH daily (c-ii) or weekly (c-iii) compared with that in controls (c-i). The decrease in $\beta$-catenin content was greater in the mice treated with ACTH once a day (c-ii). Expression of glycogen synthase kinase-3 $\beta$ in luminal epithelium and glandular epithelium was lower in mice treated with oestradiol and ACTH daily (d-ii) or weekly $(\mathrm{d}$-iii) than in controls $(\mathrm{d}-\mathrm{i})$. The weekly treatment schedule resulted in a greater reduction in glycogen synthase kinase-3ß content (d-iii). Scale bars represent (a-i-iii) $110 \mu \mathrm{m}$ and (b-i-iii, c-i-iii, d-i-iii) $50 \mu \mathrm{m}$. 


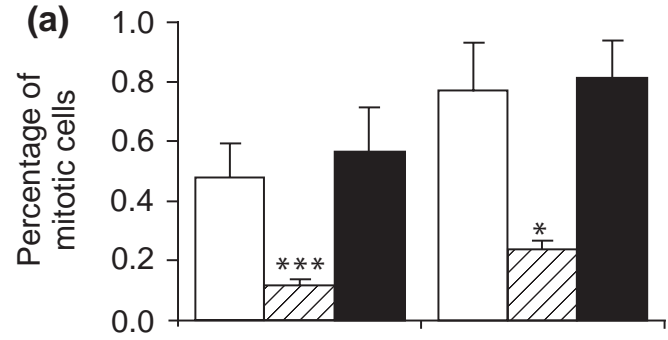

(c)

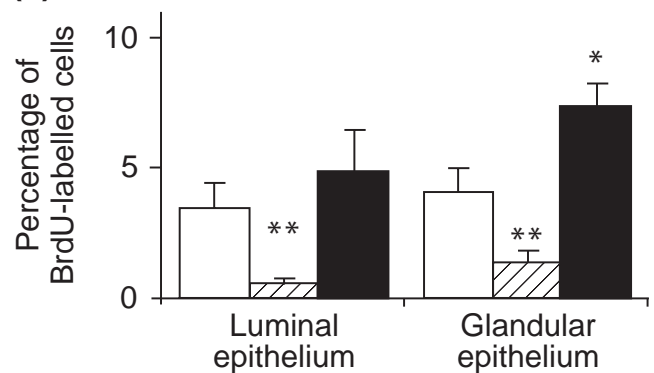

(b)

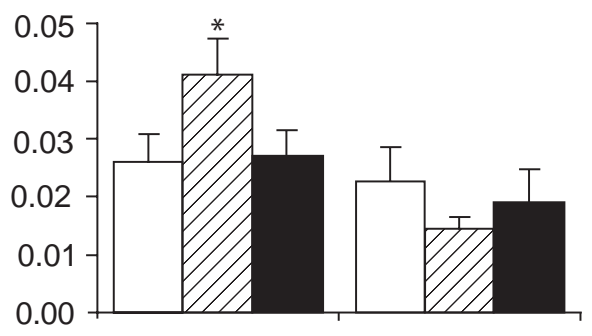

(d)

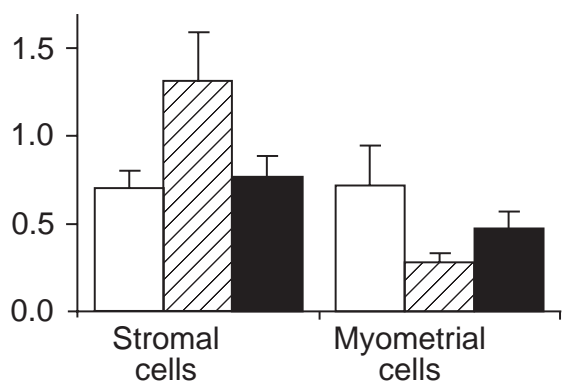

Fig. 3. The numbers of $(a, b)$ mitotic and (c,d) bromodeoxyuridine (BrdU)-labelled cells in uterine compartments of ovariectomized mice treated with oestradiol and adrenocorticotrophic hormone (ACTH) once a day $(\Xi)$ or once a week $(\boldsymbol{\square})$ for 30 days compared with those in mice treated with oestradiol and saline (control, $\square)\left(n=11\right.$ per group). Values are means \pm SEM. ${ }^{*} P<0.05$, ${ }^{* *} P<0.01,{ }^{* * *} P<0.001$ compared with controls (significance of differences; Mann-Whitney $U$ test).

epithelium and in the epithelium of endometrial glands. There was also a decrease in both proliferative parameters in myometrial cells, but it was less pronounced than that in the epithelial tissues. In endometrial stromal cells, a marked increase in the number of mitotic and BrdU-labelled cells was detected in animals treated with oestradiol and ACTH once a day (Fig. 3). In animals treated with oestradiol and ACTH once a week, both proliferative parameters in all tissues were almost unchanged compared with those in mice treated with oestradiol and saline (Fig. 3).

\section{Glucocorticoid receptor}

Immunohistochemistry was performed to determine the localization and expression of glucocorticoid receptor in the uterine tissues. Immunoreactivity for glucocorticoid receptor was observed in the nuclei of luminal and glandular epithelia, endometrial stromal cells and smooth myocytes of the myometrium in all groups of mice used in the experiments. Treatments with oestradiol and ACTH once a day or once a week resulted in a decrease in the expression of glucocorticoid receptors in all tissues (Fig. 4). Treatment with $\mathrm{ACTH}$ once a day resulted in a greater reduction in the expression of glucocorticoid receptor than that observed with the weekly treatment with ACTH. However, these differences were significant only in epithelial uterine tissues (Fig. 4).

\section{Oestrogen receptor $\alpha$}

Immunohistochemistry was used to determine the expression of oestrogen receptor $\alpha$. Receptors were found in luminal and glandular epithelia, stromal and myometrial cells. Treatment with ACTH once a day led to a reduction in the expression of oestrogen receptor $\alpha$ in all uterine compartments (Figs 1 and 4). Treatment with ACTH once a week led to a small increase in the expression of oestrogen receptor $\alpha$ in all uterine tissues, with the exception of glandular epithelium, in which the expression was markedly augmented (Figs 1 and 4).

\section{$\beta$-Catenin and glycogen synthase kinase- $3 \beta$}

$\beta$-Catenin is a key component of adhesion junctions and the Wnt signalling pathway (Miller et al., 1999). Synthesis and expression of $\beta$-catenin in the uterus are affected by oestrogens and $\beta$-catenin plays a role in endometrial carcinogenesis (Nei et al., 1999). In the present study, $\beta$-catenin and glycogen synthase kinase- $3 \beta$ were detected using indirect immunohistochemical staining. Immunoreactivity for both $\beta$-catenin and glycogen synthase kinase- $3 \beta$ was found in luminal and glandular epithelia (Figs 1 and 5). Positive immunostaining for glycogen synthase kinase-3 $\beta$ was also observed in the myometrium, but localization of the enzyme in this tissue was not analysed in 

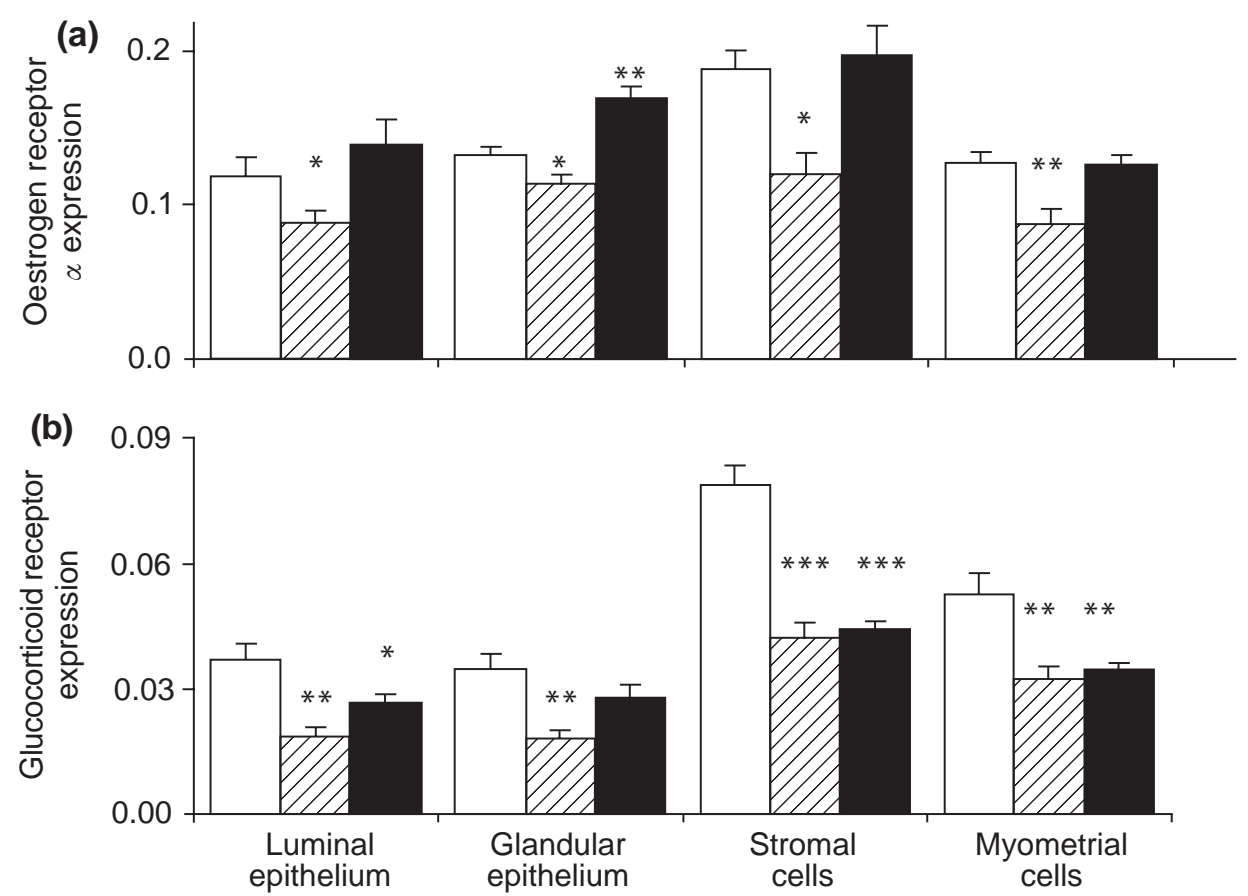

Fig. 4. Expression of (a) oestrogen receptor $\alpha$ and (b) glucocorticoid receptor in uterine tissues of mice treated with oestradiol and adrenocorticotrophic hormone (ACTH) once a day $(\square)$ or once a week (ם) for 30 days compared with that in mice treated with oestradiol and saline (control, $\square$ ) ( $n=11$ per group). The quantitation of immunostaining was performed by determination of absorbance (absorbance $=\lg \left(F_{0} / F\right)$ ) for positively stained components of a tissue, by measuring the intensity of light passing through equivalent areas occupied by positively stained structures $(F)$ and by structures with no staining $\left(F_{0}\right)$. The intensity of light passing through the nuclei $(F$; positive staining) and through the cytoplasm $\left(F_{0}\right.$; negative staining) was measured. The value of absorbance was used as the level of expression. Values are means \pm SEM. ${ }^{*} P<0.05$; ${ }^{* *} P<0.01$; *** $P<0.001$ compared with controls (significance of differences; Mann-Whitney $U$ test).

the present study. The expression of $\beta$-catenin in luminal and glandular epithelia was lower in both groups of mice treated with oestradiol and $\mathrm{ACTH}$, independent of the regimen of $\mathrm{ACTH}$ administration; however, there was a greater reduction in expression of $\beta$-catenin in mice treated with ACTH once a day (Figs 1 and 5). The expression of glycogen synthase kinase- $3 \beta$ in luminal and glandular epithelia was also reduced in both groups treated with ACTH, compared with that in mice treated with oestradiol and saline (Figs 1 and 5). A greater reduction in the expression of glycogen synthase kinase- $3 \beta$ was observed in the group that received oestradiol and ACTH once a week (Figs 1 and 5).

\section{Control groups with no oestrogen treatment}

Mice treated with olive oil in place of oestradiol plus ACTH once a day or once a week for 30 days were also used as controls. In mice treated with olive oil plus ACTH once a day or once a week, the mass of the thymus was smaller and the mass of the adrenal gland was greater compared with those in mice treated with olive oil and saline. However, in the absence of oestradiol, there were no detectable differences in all parameters examined in all uterine tissues (data not shown).

\section{Discussion}

A synthetic analogue of ACTH with long-acting potency, Synacthen depot $\left(\mathrm{ACTH}^{1-24}\right)$, was used in this study. Results showed that the mass of the thymus was reduced and mass of the adrenal gland was increased after treatment of mice with this form of ACTH. A daily treatment regimen produced more marked changes in these parameters than did a weekly treatment protocol. These data show that the treatment regimens used were effective in inducing a general chronic hypercorticosteroid effect.

Uterine mass may depend on the number of uterine cells, the size of the cells and on the water content of the uterus. Oestradiol affects all of these parameters (Couse and Korach, 1999; Gunin et al., 2001). In animals treated with $\mathrm{ACTH}$ once a day, a decrease in uterine mass was accompanied by a decrease in the proliferation of epithelial and myometrial cells and by an increase in the proliferation of endometrial stromal cells. In animals treated with ACTH 


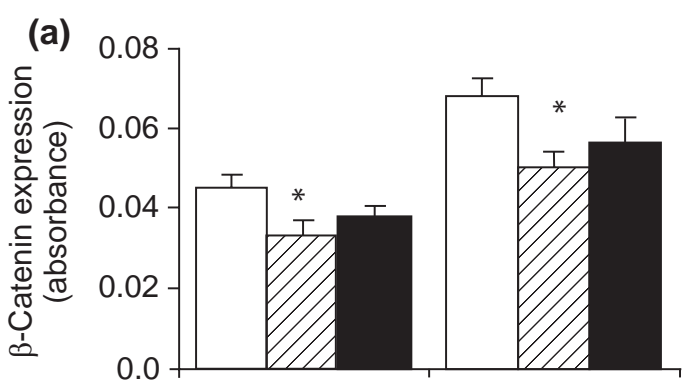

(b)

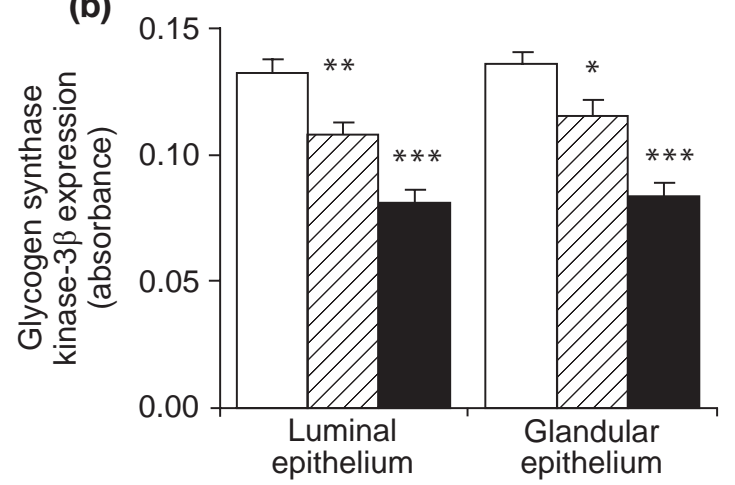

Fig. 5. Expression of (a) $\beta$-catenin and (b) glycogen synthase kinase-3 $\beta$ in uterine tissues of mice treated with oestradiol and adrenocorticotrophic hormone (ACTH) once a day $(\square)$ or once a week ( $\mathbf{\square})$ for 30 days compared with that in mice treated with oestradiol and saline (control, $\square$ ) ( $n=11$ per group). The quantitation of immunostaining was performed by determination of absorbance (absorbance $=\lg \left(F_{0} / F\right)$ ) for positively stained components of a tissue, by measuring the intensity of light passing through equivalent areas occupied by positively stained structures $(F)$ and by structures with no staining $\left(F_{0}\right)$. The intensity of light passing through the cytoplasm of uterine epithelial cells ( $F$; positive staining) and through the endometrial stromal cells ( $F_{0}$; negative staining) was used. The value of absorbance was used as the level of expression. Values are means \pm SEM. ${ }^{*} P<0.05 ;{ }^{* *} P<0.01$; ${ }^{* * *} P<0.001$ compared with controls (significance of differences; MannWhitney $U$ test).

once a week, an increase in uterine mass was associated with almost no changes in cell proliferation. Therefore, it is proposed that changes in uterine mass produced by treatment with ACTH depend mainly on water content.

In the present study, uterine glands of an abnormal shape and with abnormal types of epithelium and different types of endometrial hyperplasia, including atypical hyperplasia, which has a non-favorable prognosis and is regarded as a precancerous state (Schlesinger et al., 1999; Deligdisch, 2000), appeared after oestradiol treatment for 30 days. Treatments involving ACTH in combination with oestradiol resulted in a marked reduction in these oestrogen-induced morphogenetic changes in the uterus. Both ACTH treatments produced similar changes in uterine histology. However, treatment with ACTH once a week resulted in less pronounced changes. It can be assumed that ACTH, independent of the treatment regimen, prevents oestrogen- induced morphogenetic changes and formation of hyperplasia.

Histological data from the present study differs partially from the results of our previous work involving treatment with oestradiol and the glucocorticoid dexamethasone (Gunin et al., 2001). The previous work showed that dexamethasone blocks oestradiol-induced morphogenetic alterations in the uterus and prevents formation of atypical hyperplasia, but in some cases also causes formation of cystic hyperplasia (Gunin et al., 2001). However, in the present study, no cases of cystic hyperplasia were observed after treatment with ACTH once a day, and only a small number of cases of cystic hyperplasia occurred in animals that received $\mathrm{ACTH}$ once a week. Therefore, it can be concluded that the action of ACTH on oestrogen-dependent morphogenesis in the uterus is similar to that of dexamethasone, but is not the same.

Proliferative processes were assessed by determining the number of mitotic and BrdU-labelled cells. These parameters show how many cells are in the $\mathrm{M}$ or $\mathrm{S}$ phase, respectively, of the cell cycle. Treatment with oestradiol and ACTH once a week has almost no influence on proliferative processes in the uterus. However, treatment with oestradiol together with daily injections of ACTH resulted in a decrease in the number of mitotic and BrdU-labelled cells in epithelial uterine structures, and an increase in these parameters in stromal and myometrial cells. The present results on cell proliferation also differ from those obtained after treatment with oestradiol and dexamethasone, in which decreased proliferation was observed in all uterine tissues (Gunin et al., 2001). The effect of ACTH administered once a day on proliferation in the uterus is similar to that of progesterone, which blocks proliferation in uterine epithelia and augments proliferation in stromal and myometrial cells (Martin et al., 1973b; Tong and Pollard, 1999). However, progesterone has a specific effect on oestrogendependent morphogenesis in the uterus (Finn et al., 1995), which is different from the effect of either ACTH or dexamethasone administration (Gunin et al., 2001). The effect of daily treatment with ACTH on proliferation in the uterus is also similar to that of the synthetic glucocorticoid triamcinolone, which can also interact with progesterone receptors (Panko et al., 1981). It is likely that the effect of ACTH depends mainly on corticosterone, which is a natural glucocorticoid in rodents, has both gluco- and mineralocorticoid activities (Panko et al., 1981; Handa et al., 1994), and can interact with progesterone receptors (Panko et al., 1981; Handa et al., 1994). It is possible that mineralocorticoid receptors are also involved in the action of corticosterone on oestrogen-dependent processes in the uterus.

Expression of oestrogen and glucocorticoid receptors, $\beta$ catenin and glycogen synthase kinase- $3 \beta$ in uterine tissues was examined to determine the possible mechanisms involved in the action of ACTH on oestrogen-induced effects in the uterus. The expression of glucocorticoid receptor in all uterine tissues was reduced under both $\mathrm{ACTH}$ treat- 
ments; however, the reduction was less pronounced in the weekly treatment protocol. An analogous situation was reported after glucocorticoid exposure in the uterus (Bamberger et al., 1996; Ray, 1996). A decrease in the expression of the glucocorticoid receptor, as occurred after chronic ACTH administration, can be regarded as autodownregulation of the receptors and may be due to an increase in the rate of degradation of the receptors or to a decrease in the rate of synthesis (Schmidt and Meyer, 1994; Bamberger et al., 1996). Data on glucocorticoid receptor showed that this receptor system did not remain intact or insensitive to ACTH treatments. Therefore it appears that the effects of ACTH on the uterine parameters tested are mediated via increased expression of glucocorticoids and via glucocorticoid receptor.

In the present study, the expression of oestrogen receptor $\alpha$ was low in all uterine compartments in animals that received oestradiol and $\mathrm{ACTH}$ once a day; however, weekly administration of ACTH led to a small increase in the expression of oestrogen receptor $\alpha$ in uterine tissues. Hence, differences between the effect of daily and weekly administration of ACTH on uterine histology and cell proliferation may be due to changes in the expression of oestrogen receptor $\alpha$. This contention is supported by previous data that showed a decrease in oestrogen receptor content in the uterus after treatment with glucocorticoids (Atkinson and Adams, 1988; Zamorano et al., 1992). The effects of ACTH on all parameters tested were seen only in oestrogen-treated mice and were not observed in control animals that received olive oil in place of oestradiol, which indicates that ACTH affects the mechanism of oestrogen action. However, it remains unclear how different doses of ACTH influence the expression of oestrogen receptors in a dissimilar manner.

$\beta$-Catenin, a component of adhesion junctions and the Wnt signalling pathway, can be phosphorylated by glycogen synthase kinase-3 $\beta$, followed by its degradation (Miller et al., 1999; Schlesinger et al., 1999; Jan and Jan, 2000). However, in the present study, the results obtained with $\mathrm{ACTH}$ treatment once a day showed that concentrations of both compounds decreased. Hence, in this study, the decrease in the expression of $\beta$-catenin was not due to glycogen synthase kinase-3 $\beta$, but was probably caused by a decrease in $\beta$-catenin biosynthesis. Therefore, a reduction in the expression of glycogen synthase kinase- $3 \beta$ in uterine tissues, which was observed after daily treatment with $\mathrm{ACTH}$, may be considered a compensatory reaction against decreased synthesis and expression of $\beta$-catenin. However, weekly treatment with $\mathrm{ACTH}$ resulted in a smaller decrease in the concentration of $\beta$-catenin and a greater reduction in the concentration of glycogen synthase kinase- $3 \beta$ in uterine epithelia. In this case, the increase in $\beta$-catenin probably depends, at least in part, on the reduced content of glycogen synthase kinase- $3 \beta$.

The present results show that ACTH treatment results in a decrease in the expression of $\beta$-catenin and glycogen synthase kinase- $3 \beta$ and prevents the development of endometrial hyperplasia. However, in a study involving combined treatment with oestradiol and dexamethasone there was an increase in the expression of both $\beta$-catenin and glycogen synthase kinase- $3 \beta$ and a reduction in the incidence of endometrial hyperplasia (Gunin et al., 2001; A. G. Gunin, A. S. Tolmachev and V. Emelianov, unpublished). Dexamethasone prevents the formation of non-favourable types of endometrial hyperplasia, such as atypical hyperplasia, but leads to the formation of cystic hyperplasia (Gunin et al., 2001). However, ACTH does not result in formation of cystic hyperplasia. Normal proliferative endometrium and simple hyperplasia were found in most animals after treatment with ACTH. It is likely that these differences, little for the first view, are due to distinctions in work of regulatory systems that regulate cell and tissue shape. As stated earlier, $\beta$-catenin and glycogen synthase kinase- $3 \beta$ play a role in the same events, namely supporting cell fate, shape and differentiation (Miller et al., 1999; Jan and Jan, 2000). Hence, differences in the actions of dexamethasone and ACTH on oestrogen-induced hyperplasia formation are probably associated with distinct patterns of expression of $\beta$-catenin and glycogen synthase kinase-3 $\beta$. It should be noted that the role of $\beta$-catenin in the development of cancer is not clear at present. Some studies have indicated that increased expression of $\beta$-catenin is associated with cancer formation (Calvisi et al., 2001; Semba et al., 2001), enhanced proliferation (Ito et al., 2000; Kuhnen et al., 2000; Sellin et al., 2001) and impaired apoptosis (Cadoret et al., 2001; Ling et al., 2001). There are also studies indicating that $\beta$-catenin has anti-tumour activity (Fujimoto et al., 1998; Miyamoto et al., 2000). Therefore, it is not possible to explain the differences in the expression of $\beta$-catenin and glycogen-synthase kinase- $3 \beta$ that occurred after treatment with dexamethasone and $\mathrm{ACTH}$. It is only possible to speculate that these compounds are involved in the actions of these hormones.

In the present study, high doses of ACTH (daily injections) inhibited almost all of the actions of oestrogen, whereas low doses of ACTH (weekly injections) had different effects on the actions of oestrogen in the uterus; oestrogen-induced increases in uterine mass were enhanced, but oestrogen-induced morphogenetic changes and hyperplasia formation were inhibited, and proliferation was almost unchanged. It is suggested that each oestrogendependent effect in the uterus may have a unique regulatory mechanism. Each mechanism can be affected differently by the same dose and by different doses of ACTH or glucocorticoids. Moreover, in addition to differences in the number of oestrogen and glucocorticoid receptors, the occupancy of these receptors by their ligands also may be different, especially for glucocorticoid hormones, the content of which must be different between daily and weekly $\mathrm{ACTH}$ treatments. It is known that $\mathrm{ACTH}$ and its precursor, pro-opiomelanocortin, can be synthesized in the uterus, and ACTH binding sites are also present in this organ (Gravanis et al., 1999; Fadalti et al., 2000). In addition, proopiomelanocortin and derived peptides, including $\mathrm{ACTH}$, are thought to have paracrine effects in the uterus (Clifton 
et al., 1998; Gravanis et al., 1999). Therefore, ACTH may have a direct effect on uterine sensitivity to oestrogens. However, further studies are needed to elucidate fully the mechanisms of action of ACTH on oestrogen-dependent processes in the uterus.

This work was partially supported by grants from the Russian Foundation for Basic Research (00-04-48043), from the President of the Russian Federation for Young Doctors in Science (00-15-99365). The authors are very grateful to Miho Takahashi (Mitsubisi Kasei Institute of Life Science, Tokyo, Japan) for provision of the antiglycogen synthase kinase- $3 \beta$ polyclonal antibody. They also sincerely thank Vladimir Botchkarev (Department of Dermatology, Boston University Medical School, Boston, USA) for reagents and for helpful comments on the manuscript.

\section{References}

Atkinson S and Adams NR (1988) Adrenal glands alter the concentration of oestradiol-17 beta and its receptor in the uterus of ovariectomized ewes Journal of Endocrinology 118 375-380

Bamberger CM, Schulte HM and Chrousos GP (1996) Molecular determinants of glucocorticoid receptor function and tissue sensitivity to glucocorticoids Endocrine Reviews 17 245-261

Bigsby RM (1993) Progesterone and dexamethasone inhibition of estrogeninduced synthesis of DNA and complement in rat uterine epithelium: effects of antiprogesterone compounds Journal of Steroid Biochemistry and Molecular Biology 45 295-301

Cadoret A, Ovejero C, Saadi Kheddouci S, Souil E, Fabre M, Romagnolo B, Kahn A and Perret C (2001) Hepatomegaly in transgenic mice expressing an oncogenic form of beta-catenin Cancer Research 61 3245-3249

Calvisi DF, Factor VM, Loi R and Thorgeirsson SS (2001) Activation of betacatenin during hepatocarcinogenesis in transgenic mouse models: relationship to phenotype and tumor grade Cancer Research 61 2085-2091

Campbell PS (1978) The mechanism of the inhibition of uterotrophic responses by acute dexamethasone pretreatment Endocrinology 103 716-723

Clifton VL, Telfer JF, Thompson AJ, Cameron IT, Teoh TG, Lye SJ and Challis JR (1998) Corticotropin-releasing hormone and proopiomelanocortinderived peptides are present in human myometrium Journal of Clinical Endocrinology and Metabolism 83 3716-3721

Couse JF and Korach KS (1999) Estrogen receptor null mice: what have we learned and where will they lead us? Endocrine Reviews 20 358-417

Deligdisch L (2000) Hormonal pathology of the endometrium Modern Pathology 13 285-294

Emons G, Fleckenstein G, Hinney B, Huschmand A and Heyl W (2000) Hormonal interactions in endometrial cancer Endocrine Related Cancer $7227-242$

Fadalti M, Pezzani I, Cobellis L, Springolo F, Petrovec MM, Ambrosini G, Reis FM and Petraglia F (2000) Placental corticotropin-releasing factor. An update Annals of the New York Academy of Sciences 900 89-94

Finn CA, Pope M and Milligan SR (1995) Control of uterine stromal mitosis in relation to uterine sensitivity and decidualization in mice Journal of Reproduction and Fertility 103 153-158

Fujimoto J, Ichigo S, Hori M and Tamaya T (1998) Expressions of E-cadherin and alpha- and beta-catenin mRNAs in uterine endometrial cancers European Journal Gynaecological Oncology 19 78-81

Gravanis A, Stournaras C and Margioris AN (1999) Paracrinology of endometrial neuropeptides: corticotropin-releasing hormone and opioids Seminars in Reproductive Endocrinology 17 29-38

Gunin A (1998) Effect of long-term glucocorticoid treatment on oestradiolinduced proliferation in the uterus of ovariectomized rats Journal of Endocrinology 157 481-488

Gunin AG, Sharov AA and Nikolaev DV (2000) Two month glucocorticoid treatment increases estradiol-induced stromal and myometrial cell proliferation in the uterus of ovariectomized rats European Journal of Obstetrics and Gynecology and Reproductive Biology 88 171-179
Gunin AG, Mashin IN and Zakharov DA (2001) Proliferation, mitosis orientation and morphogenetic changes in the uterus of mice following chronic treatment with both estrogen and glucocorticoid hormones Journal of Endocrinology 169 23-31

Gunin AG, Emelianov V, Tolmachev AS and Tolmacheva A (2002) Effect of prolactin and dopaminergic drugs on uterine response to chronic estrogen exposure Journal of Endocrinology 172 61-69

Handa RJ, Burgess LH, Kerr JE and O'Keefe JA (1994) Gonadal steroid hormone receptors and sex differences in the hypothalamo-pituitaryadrenal axis Hormones and Behavior 28 464-476

Ito T, Yorioka N, Yamamoto M, Kataoka K and Yamakido M (2000) Effect of glucose on intercellular junctions of cultured human peritoneal mesothelial cells Journal of the American Society for Nephrology 11 1969-1979

Jan YN and Jan LY (2000) Polarity in cell division: what frames thy fearful asymmetry? Cell 100 599-602

Kuhnen C, Herter P, Muller O, Muehlberger T, Krause L, Homann $\mathrm{H}$, Steinau HU and Muller KM (2000) Beta-catenin in soft tissue sarcomas: expression is related to proliferative activity in high-grade sarcomas Modern Pathology 13 1005-1013

Liehr JG (2000) Is estradiol a genotoxic mutagenic carcinogen? Endocrine Reviews 21 40-54

Ling Y, Zhong Y and Perez Soler R (2001) Disruption of cell adhesion and caspase-mediated proteolysis of beta- and gamma-catenins and APC protein in paclitaxel-induced apoptosis Molecular Pharmacology $\mathbf{5 9}$ 593-603

Markaverich BM, Upchurch S and Clark JH (1981) Progesterone and dexamethasone antagonism of uterine growth: a role for a second nuclear binding site for estradiol in estrogen action Journal of Steroid Biochemistry 14 125-132

Martin L, Finn CA and Trinder G (1973a) Hypertrophy and hyperplasia in the mouse uterus after oestrogen treatment: an autoradiographic study Journal of Endocrinology 56 133-144

Martin L, Finn CA and Trinder G (1973b) DNA synthesis in the endometrium of progesterone-treated mice Journal of Endocrinology $\mathbf{5 6}$ 303-307

Miller JR, Hocking AM, Brown JD and Moon RT (1999) Mechanism and function of signal transduction by the $\mathrm{Wnt} /$ beta-catenin and $\mathrm{Wnt} / \mathrm{Ca}^{2+}$ pathways Oncogene 18 7860-7872

Miyamoto S, Baba H, Kuroda S, Kaibuchi K, Fukuda T, Maehara Y and Saito T (2000) Changes in E-cadherin associated with cytoplasmic molecules in well and poorly differentiated endometrial cancer British Journal of Cancer 83 1168-1175

Monheit AG and Resnik R (1981) Corticosteroid suppression of estrogeninduced uterine blood flow in nonpregnant sheep American Journal of Obstetrics and Gynecology 139 454-458

Nei H, Saito T, Yamasaki H, Mizumoto H, Ito E and Kudo R (1999) Nuclear localization of beta-catenin in normal and carcinogenic endometrium Molecular Carcinogenesis 25 207-218

Niwa K, Morishita S, Hashimoto M, Itoh T, Fujimoto J, Mori H and Tamaya $\mathbf{T}$ (1998) Effects of tamoxifen on endometrial carcinogenesis in mice Japanese Journal of Cancer Research 89 502-509

Panko WB, Clark JH and Walters MR (1981) Glucocorticoid receptors: documentation in the rat uterus Journal of Receptor Research 2 29-45

Rabin DS, Johnson EO, Brandon DD, Liapi C and Chrousos GP (1990) Glucocorticoids inhibit estradiol-mediated uterine growth: possible role of the uterine estradiol receptor Biology of Reproduction 42 74-80

Ray D (1996) Molecular mechanisms of glucocorticoid resistance Journal of Endocrinology 149 1-5

Sahlin L (1995) Dexamethasone attenuates the estradiol-induced increase of IGF-I mRNA in the rat uterus Journal of Steroid Biochemistry and Molecular Biology 55 9-15

Schlesinger A, Shelton CA, Maloof JN, Meneghini M and Bowerman B (1999) Wnt pathway components orient a mitotic spindle in the early Caenorhabditis elegans embryo without requiring gene transcription in the responding cell Genes and Development 13 2028-2038

Schmidt TJ and Meyer AS (1994) Autoregulation of corticosteroid receptors. How, when, where, and why? Receptor 4 229-257

Scully RE, Bonfiglio TA, Kurman RJ, Silverberg SG and Wilkinson EJ (1994) 
Histological Typing of Female Genital Tract Tumours (International Histological Classification of Tumours) 2nd Edn, WHO Geneva pp 13-18

Sellin JH, Umar S, Xiao J and Morris AP (2001) Increased beta-catenin expression and nuclear translocation accompany cellular hyperproliferation in vivo. Cancer Research 61 2899-2906

Semba S, Han SY, Ikeda H and Horii A (2001) Frequent nuclear accumulation of beta-catenin in pituitary adenoma Cancer 91 42-48

Stewart PJ, Zaloudek CJ, Inman MM and Webster RA (1983) Effects of dexamethasone and indomethacin on estrogen-induced uterine growth Life Sciences 33 2349-2356

Takahashi M, Tomizawa K and Ishiguro K (2000) Distribution of tau protein kinase $\mathrm{I} /$ glycogen synthase kinase-3beta, phosphatases $2 \mathrm{~A}$ and $2 \mathrm{~B}$, and phosphorylated tau in the developing rat brain Brain Research 857 193-206

Tchernitchin A, Rooryck J, Tchernitchin X, Vandenhende J and Galand P
(1975) Effects of cortisol on uterine eosinophilia and other oestrogenic responses Molecular and Cellular Endocrinology 2 331-337

Tong W and Pollard JW (1999) Progesterone inhibits estrogen-induced cyclin D1 and cdk4 nuclear translocation, cyclin E- and cyclin A-cdk2 kinase activation, and cell proliferation in uterine epithelial cells in mice Molecular and Cellular Biology 19 2251-2264

Zamorano P, Steinsapir J and Mahesh VB (1992) Effect of 5 alphadihydrotestosterone and dexamethasone on estrogen receptors of the anterior pituitary and uterus Steroids $\mathbf{5 7} 18-26$

Zennaro M-C (1998) Syndromes of glucocorticoid and mineralocorticoid resistance European Journal of Endocrinology 139 127-138

Received 20 September 2001.

First decision 4 December 2001

Accepted 19 December 2001. 